during labour. Elucidating these multiple pathways will be the only way we can go forward in the prevention of newborn encephalopathy.

For acknowledgements and details of contributors, funding, and competing interests please see the accompanying paper.

1 Nelson KB, Leviton A. How much of neonatal encephalopathy is due to birth asphyxia? Am J Dis Child 1991;145:1325-31

2 Finer NN, Robertson CM, Richards RT, Pinnell LE, Peters KL. Hypoxicischemic encephalopathy in term neonates: perinatal factors and outcome. J Pediatr 1981;98:112-7.

3 Ergander U, Eriksson M, Zetterstrom R. Severe neonatal asphyxia. Incidence and prediction of outcome in the Stockholm area. Acta Paediatr 1983;72:321-5.

4 Levene ML, Kornberg J, Williams THC. The incidence and severity of post-asphyxial encephalopathy in full-term infants. Early Hum Develop $1985 ; 11: 21-6$.

5 Hull J, Dodd KL. Falling incidence of hypoxic-ischaemic encephalopathy in term infants. Br J Obstet Gynaecol 1992;99:386-91.

6 Thornberg E, Thiringer K, Odeback A, Milsom I. Birth asphyxia: incidence, clinical course and outcome in a Swedish population. Acta Paediatr 1995;84:927-32

7 Sarnat HB, Sarnat MS. Neonatal encephalopathy following fetal distress. Arch Neurol 1976;33:696-705.

8 Badawi N, Kurinczuk JJ, Keogh JM, Alessandri LM, O'Sullivan F, Burton PR, et al. Antepartum risk factors for newborn encephalopathy: the Western Australian case-control study. BMJ 1998;317:1549-53.

9 Committee on Fetus and Newborn, American Academy of Paediatrics, and Committee on Obstetric Practice, American College of Obstetricians and Gynecologists. Use and abuse of the Apgar score. Pediatrics 1996;98:141-2.
10 Berg AT. Indices of fetal growth retardation, perinatal hypoxia-related factors and childhood neurological morbidity. Early Hum Dev 1989;19:271-83.

11 Spencer JAD, Badawi N, Burton PR, Keogh JM, Pemberton PJ, Stanley FJ The intrapartum CTG prior to neonatal encephalopathy at term: a case control study. Br J Obstet Gynaecol 1997;104:25-8.

12 Adamson SJ, Alessandri LM, Badawi N, Burton PR, Pemberton PJ, Stanley FJ. Predictors of neonatal encephalopathy in full term infants. BMJ 1995;311:598-602

13 Grether JK, Nelson KB. Maternal infection and cerebral palsy in infants of normal birth weight. JAMA 1997;278:207-11

14 Murphy DJ, Hope PL, Johnson A. Neonatal risk factors for cerebral palsy in very preterm babies: case-control study. BMJ 1997;314:404-8.

15 Leviton A. Preterm birth and cerebral palsy: is tumour necrosis factor the missing link? Dev Med Child Neurol 1993;35:553-8.

16 Gee V. Perinatal statistics in Western Australia: 12th Annual Report of the Western Australian Midwives Notification System for 1994. Perth: Health Department of Western Australia, 1995.

17 Ziegler AL, Calame A, Marchand C, Passera M, Reymond-Goni I, Prod'Hom LS. Cerebral distress in full-term newborns and its prognostic value. A follow-up study of 90 infants. Helvetica Paediatrica Acta 1976;31:299-317.

18 De Souza SW, Richards B. Neurological sequelae in newborn babies after perinatal asphyxia. Arch Dis Child 1978;53:564-9.

19 van Ham MAPC, van Dongen PWJ, Mulder J. Maternal consequences of caesarean section. A retrospective study of intra-operative and post-operative maternal complications of caesarean section during a 10 year period. Eur J Obstet Gynecol Reprod Biol 1997;74:1-6.

20 Lumley J, Lester A, Renou P, Wood C. A failed RCT to determine the best method of delivery for very low birth weight infants. Cont Clin Trials $1985 ; 6: 120-7$

(Accepted 27 August 1998)

\title{
Subdural haemorrhages in infants: population based study
}

\author{
S Jayawant, A Rawlinson, F Gibbon, J Price, J Schulte, P Sharples, J R Sibert, A M Kemp
}

Editorial by Lloyd
Department of
Child Health,
University of Wales
College of
Medicine, Academic
Centre, Llandough
Hospital, Penarth,
Vale of Glamorgan
CF64 2XX
A M Kemp,
senior lecturer
J R Sibert,
professor
S Jayawant,
senior registrar
A Rawlinson,
consultant
paediatrician
F Gibbon,
consultant in
paediatric neurology
Department of
Child Health,
Southmead
Hospital, Bristol
BS10 5NB
J Price,
consultant
paediatrician
continued over

continued over

BMJ 1998;317:1558-6

\begin{abstract}
Objectives To identify the incidence, clinical outcome, and associated factors of subdural haemorrhage in children under 2 years of age, and to determine how such cases were investigated and how many were due to child abuse.

Design Population based case series.

Setting South Wales and south west England.

Subjects Children under 2 years of age who had a subdural haemorrhage. We excluded neonates who developed subdural haemorrhage during their stay on a neonatal unit and infants who developed a subdural haemorrhage after infection or neurosurgical intervention.
\end{abstract}

Main outcome measures Incidence and clinical outcome of subdural haemorrhage in infants, the number of cases caused by child abuse, the investigations such children received, and associated risk factors.

Results Thirty three children (23 boys and 10 girls) were identified with subdural haemorrhage. The incidence was 12.8/100 000 children/year (95\% confidence interval 5.4 to 20.2). Twenty eight cases $(85 \%)$ were under 1 year of age. The incidence of subdural haemorrhage in children under 1 year of age was 21.0/100 000 children/year and was therefore higher than in the older children. The clinical outcome was poor: nine infants died and 15 had profound disability. Only 22 infants had the basic investigations of a full blood count, coagulation screen, computed tomography or magnetic resonance imaging, skeletal survey or bone scan, and ophthalmological examination. In retrospect, 27 cases $(82 \%)$ were highly suggestive of abuse.

Conclusion Subdural haemorrhage is common in infancy and carries a poor prognosis; three quarters of such infants die or have profound disability. Most cases are due to child abuse, but in a few the cause is unknown. Some children with subdural haemorrhage do not undergo appropriate investigations. We believe the clinical investigation of such children should include a full multidisciplinary social assessment, an ophthalmic examination, a skeletal survey supplemented with a bone scan or a skeletal survey repeated at around 10 days, a coagulation screen, and computed tomography or magentic resonance imaging. Previous physical abuse in an infant is a significant risk factor for subdural haemorrhage and must be taken seriously by child protection agencies.

\section{Introduction}

Subdural haemorrhage in infants and young children presents major challenges in diagnosis to doctors, social workers, and courts. It has been recognised as a form of severe child abuse as far back as 1860, but little is known about the epidemiology or prognosis of the condition. ${ }^{1-4}$ In clinical practice, it is often difficult to deduce whether a subdural haematoma in an infant is caused by accident or abuse. ${ }^{5}$ The shaken baby syndrome is well described both clinically and pathologically, but there are few epidemiological accounts of this condition that is associated with death and disability. ${ }^{6}$

We performed a population based case series study of children under the age of 2 years who had a 
subdural haemorrhage. We aimed to identify the incidence and outcome of the condition, and to determine how many cases were due to child abuse, what investigations these children received, and associated factors.

\section{Subjects and methods}

We undertook a three year retrospective study (1 January 1993 to 31 December 1995) of all children under the age of 2 years with subdural haemorrhage. Diagnosis was confirmed by computed tomography, magnetic resonance imaging, or post mortem examination. We excluded neonates who developed subdural haemorrhage during their stay on a neonatal unit and infants who sustained a subdural haemorrhage after infection or neurosurgical intervention.

We identified cases from South Wales (the old counties of Gwent, South Glamorgan, Mid Glamorgan, West Glamorgan, Dyfed, and South Powys) and south west England (Gloucester and Avon). The children were treated at tertiary neurosurgical centres in Swansea, Cardiff, and Bristol. Population data were derived from the Office for National Statistics. ${ }^{7}$ We identified cases from ICD-9 (international classification of diseases, 9th revision) inpatient coding: 432.1, 852.0, 851.0, 852.1, 767.0, 336.1, admission books of hospital wards taking paediatric patients in the study area, and the Confidential Enquiry into Sudden Deaths in Infants. ${ }^{8}$ We also identified cases from paediatricians, neurosurgeons, pathologists, Her Majesty's coroners, and expert witnesses in child protection cases. Identification of cases was independently confirmed.

To substantiate our incidence figures for 1996 and 1997, we collected notifications of subdural haemorrhage secondary to child abuse in Wales through the Welsh Paediatric Surveillance System. This system uses a return card method similar to the British Paediatric Surveillance System. ${ }^{9}$ The notification cards are sent out monthly to all consultant paediatricians in Wales.

We extracted details about the cause of the subdural haemorrhage, its clinical presentation, investigations, neurological follow up after 1 year, and the outcome of child protection (from hospital case notes). Details were also obtained from the minutes of case conferences.

\section{Results}

We identified 33 cases (23 (69.7\%) boys and 10 (30.3\%) girls) of subdural haemorrhage in children. The incidence of subdural haemorrhage in children under 2 years of age was 12.8/100 000 children/year (95\% confidence interval 5.4 to 20.2). The age range was 3 weeks to 17 months (median age 3 months). Twenty eight cases occurred in the first year of life. The incidence of subdural haemorrhage in children under 1 year of age was 21.0/100 000 children/year (confidence interval 7.5 to 34.4). The risk of a child developing a subdural haemorrhage by 1 year of age was 1:4761 children.

The clinical outcome of cases with subdural haemorrhage was poor. Nine infants $(27.3 \%)$ died and 15 $(45.5 \%)$ had profound disability (table 1$)$. Nine infants $(27.3 \%)$ were reported as normal after 1 year of follow up. No infant had a developmental abnormality identi-

\begin{tabular}{ll}
\hline Table 1 Disabilities in 15 infants with subdural haemorrhage \\
Disability & No of cases \\
\hline Significant motor impairment: & \\
\hline Spastic quadriplegia & 4 \\
\hline Hemiplegia & 2 \\
\hline Hypotonia & 1 \\
\hline Speech and language delay & 4 \\
\hline Hearing impairment & 4 \\
\hline Blindness or visual impairment & 9 \\
\hline Ongoing seizures & 8 \\
\hline Hydrocephalus requiring shunts & 5 \\
\hline Multiple disabilities (combinations of the above) & 5 \\
\hline
\end{tabular}

Frenchay Hospital, Bristol BS16 1LE

J Schulte, consultant paediatrician

P Sharples, consultant in paediatric neurology Correspondence to: Dr Kemp kempam@cardiff.ac.uk

fied before presentation. Clinical presentation varied from infants with general malaise to critically ill infants with impaired consciousness; four (12.2\%) children were dead on arrival. Six (18.2\%) of the infants had been admitted to hospital on several occasions with symptoms of drowsiness and lethargy before a subdural haemorrhage was diagnosed. Twenty cases $(60.6 \%)$ required management in intensive care.

Twenty six $(78.8 \%)$ infants were investigated by computed tomography, four $(12.1 \%)$ by computed tomography and magnetic resonance imaging, and two $(6.1 \%)$ by magnetic resonance imaging only. Five cases were diagnosed with subdural haemorrhage at post mortem examination. The 29 infants $(87.8 \%)$ who were alive on admission had a full blood count and coagulation studies. Twenty seven infants $(81.8 \%)$ had a skeletal survey (including three infants at post mortem examination). Twenty four infants $(72.7 \%)$ had an ophthalmoscopic examination (14 were performed by an ophthalmologist), and the eyes of three infants were examined at post mortem examination. In total, only 22 infants $(66.7 \%)$ had a full series of basic investigations.

All 29 infants tested had normal coagulation, but eight $(27.6 \%)$ had serum haemoglobin concentrations $<80 \mathrm{~g} / \mathrm{l}$ on admission and six (20.7\%) had serum haemoglobin concentrations between 80 and $100 \mathrm{~g} / \mathrm{l}$. Sixteen of the 27 infants $(59.3 \%)$ who had a skeletal survey had fractures (rib (9 cases), skull (5), tibia or fibula (4), femur (2), clavicle (1), and radius (1)). General examination showed other evidence of abuse in 13 infants (39.4\%) (torn frenulum (5 cases), burns (1), adult bites (1), and bruising (10)). Two infants presented with profound hypernatraemia secondary to non-accidental poisoning with salt. Overall, there was clinical evidence of coexisting traumatic injury in 19 cases $(57.6 \%)$.

In 21 cases $(77.8 \%)$ there were abnormal ophthalmoscopic findings. Of the 27 infants that were examined, $12(44.4 \%)$ had retinal haemorrhages only, five $(18.5 \%)$ had retinal and other ocular haemorrhages, one had a retinal haemorrhage and choroid tear, one had a retinal haemorrhage and papilloedema, and two had papilloedema and venous dilation.

In one case the injury had arisen from a major road traffic accident. The child had multiple skull fractures but no retinal haemorrhages. In 14 cases a clear history of shaking was obtained, although this was never the first explanation put forward. In 18 cases there was no history of shaking, and two of these cases gave no explanation at all. It was common that carers proposed 


\begin{tabular}{|c|c|c|c|c|}
\hline Age (months) & Explanation & Investigations & Finding & Outcome \\
\hline \multirow[t]{2}{*}{7} & Fell from bouncy chair & Ophthalmoscopy & $\begin{array}{l}\text { Retinal } \\
\text { haemorrhage }\end{array}$ & Died \\
\hline & & Skeletal survey & Normal & \\
\hline \multirow[t]{2}{*}{7} & Feverish and unwell & Ophthalmoscopy & Normal & Disabled \\
\hline & & No skeletal survey & - & \\
\hline \multirow[t]{2}{*}{2} & No explanation & Ophthalmoscopy & $\begin{array}{l}\text { No findings } \\
\text { documented }\end{array}$ & Dead on arrival \\
\hline & & No skeletal survey & - & \\
\hline \multirow[t]{2}{*}{1} & No explanation & No ophthalmoscopy & - & Normal \\
\hline & & Skeletal survey & Normal & \\
\hline \multirow[t]{2}{*}{4} & Unwell & Ophthalmoscopy & Normal & Disabled \\
\hline & & Skeletal survey & Normal & \\
\hline
\end{tabular}

several different explanations for the injury; three different explanations were given in 10 cases, and two possible causes were given in eight cases. In eight cases carers denied any trauma and attributed the symptoms to some sort of infantile illness. Traumatic explanations were proposed in the remaining cases. These were not definitive, with explanations that the injury had arisen from seemingly minor traumatic events that had recently occurred.

Four of the infants (12.1\%) had previously suffered from physical abuse, and all of these children died. Of 17 cases $(51.5 \%)$ with siblings there was a history of previous sibling abuse in six $(35.3 \%)$ and concurrent abuse in two (11.8\%). Criminal proceedings were undertaken in 14 cases $(42.4 \%)$, which resulted in nine prosecutions. The alleged perpetrators were the male cohabitees in 5 cases $(35.7 \%)$, the biological father in 6 cases $(42.9 \%)$, and the mother in 3 cases $(21.4 \%)$.

Child abuse was confirmed in 21 cases $(63.6 \%)$ from the proceedings of child protection agencies and by the court of Her Majesty's coroner. We suggest that in a further six cases $(18.2 \%)$ there were findings that were highly suggestive of child abuse. These included fractures, coexisting trauma, and a family history of abuse. In five cases (15.1\%) there was no clear evidence of abuse. The histories in these cases only mentioned minor trauma or malaise, and there were no other injuries or social concerns (table 2). Three of these cases had not been fully investigated.

We conclude that there were 27 cases $(81.8 \%)$ that were highly suggestive of abuse, giving an incidence of non-accidental subdural haemorrhage in infants under 2 years of age of 10.13/100 000 children/year (95\% confidence interval 5.33 to 19.25). For 1996 and 1997 we identified 17 children under 2 years of age with a subdural haemorrhage secondary to physical child abuse in Wales (population under 2 years of age 68 286). ${ }^{6}$ There were 13 boys and four girls; fractures were recorded in nine cases $(52.9 \%)$ and bruises in eight cases $(47.0 \%)$. This gives an incidence of non-accidental subdural haemorrhage of 12.45/ 100000 children/year for children under 2 years of age (6.43 to 24.09). This is very similar to the figure we obtained for South Wales and south west England.

\section{Discussion}

Subdural haemorrhage is common in infancy, particularly in the first year of life. We believe our case ascertainment is complete, and continued surveillance of non-accidental subdural haemorrhage in children in
Wales confirms the incidence. Our paper provides the only population based case series of which we are currently aware. We show that the majority of subdural haemorrhages in children under 2 years of age are due to child abuse. We also show that the outlook for these children is poor, with a quarter dying and a half having profound disability. This confirms previous research findings. ${ }^{4}{ }^{10-12}$

The age range and the male predominance also confirm the findings of other studies. ${ }^{13}{ }^{14}$ It has been postulated that many parents believe that boys can withstand rougher handling, or cultural expectation is such that boys are expected to cry less often than girls. ${ }^{15}$

There are a number of theories as to why babies are vulnerable to subdural haemorrhage. As babies have a large head and weak neck muscles, it is likely that the whiplash mechanism sets up shearing forces within the cranium that are sufficient to tear the blood vessels that cross the relatively wide subdural space, resulting in bleeding. ${ }^{13}{ }^{16}$ It is also likely that the small size of the infant allows it to be picked up and shaken more easily than a heavier child. There are proponents of the shaken baby syndrome who suggest that shaking alone is insufficient to generate the acceleration-deceleration forces that are necessary to cause a subdural haematoma. ${ }^{17-19}$

Suggested mandatory investigations in cases of subdural haemorrhage in infants

- Full multidisciplinary social assessment

- Ophthalmoscopy by an ophthalmologist

- Skeletal survey supplemented with a bone $\operatorname{scan}^{20}$ or a repeat survey at around 10 days

- Coagulation screen

- Radiological assessment by computed tomography or magnetic resonance imaging

The correlation between fractures, multiple injuries, and subdural haemorrhages suggests that considerable violence must be involved around the time that a subdural haemorrhage is sustained. Our study confirms that a shaking injury was inflicted in many cases of subdural haemorrhage, but that subdural haemorrhages can also arise from severe trauma such as a road traffic accident.

Our study shows the clear relation between subdural haemorrhage and fractures, other traumatic injury, retinal haemorrhages, and a previous history of child abuse in the family. The coexistence of any of these factors should alert the paediatrician to the likelihood of child abuse. We are concerned, however, that a significant number of cases were not fully investigated. Vital coexisting features of child abuse may therefore be missed in the initial assessment. We recommend that certain investigations should be mandatory in the assessment of all children under 2 years of age with a subdural haemorrhage (box). Decisions about whether child abuse has occurred must then be made after consideration of all these investigation together with the multiagency child protection team.

The majority of the subdural haemorrhages in our cases were diagnosed from computed tomograms. Magnetic resonance imaging may be the investigation 
Key messages

- Subdural haemorrhage in children under 2 years of age is a relatively common occurrence. The majority are due to child abuse

- The mortality and morbidity of this condition are both high and serious

- The high probability of child abuse in cases is still not being recognised, and cases are not being investigated fully

- The clinical investigation of subdural haemorrhage must include a full series of basic investigations

- Previous child abuse in an infant is a strong risk factor for subdural haemorrhage, and social services must be aware of this in the future care plans for that child and family

of choice, however, as it has the capability of recognising small subdural haemorrhages not easily seen on computed tomograms. Magnetic resonance imaging can detect shearing injuries within the brain and indicate the age of the haemorrhage. ${ }^{21}$

Coagulation abnormalities were excluded in all cases tested. A subdural haemorrhage may rarely present in a child with a clotting disorder. ${ }^{22}$ In several of our cases there had been a significant fall in serum haemoglobin concentration at presentation. This implies that the bleed may have occurred more than 24 hours previously.

Retinal examination was performed by an ophthalmologist in less than half the cases. Three studies quote an $80 \%$ association between retinal haemorrhages and subdural haemorrhage in children. ${ }^{8324}$ Our findings are confirmatory.

Previous child abuse in the family is a significant risk factor for subdural haemorrhage in children; all the children who had been previously abused died. Child protection agencies must therefore give high priority to the protection of all current and future children in such families.

It has been suggested that the public may not recognise how harmful shaking is to a baby. The Louise Woodward case in the United States, and more recent cases in the United Kingdom, have resulted in considerable media coverage of this subject. It is therefore important to alert the public to the dangers of shaking a baby, as the National Society for the Protection of Children has recognised in its "Never Shake a Baby Campaign."15 Professional agencies dealing in child health and child protection agencies must heighten their awareness of both the diagnosis and prevention of this condition.

Contributors: SJ, AR, FG,JP,JS, PS, JRS, and AMK participated in the design, execution, analysis, and writing up of the study. SJ, AR,JP, JRS, and AMK will act as guarantors for the paper.

Funding: This study was partly funded by the Agatha Christie Trust for Children and the Wales Office of Research and Development.

Competing interest: None declared.

1 Tardieu A. Etude medico-legale sur les services et mauvais traitements exerces sur des enfants. Ann Hyg Publ Med Leg 1860;13:361-98.

2 Caffey J. Multiple fractures of long bones of children suffering from subdural haematoma. Am J Roentgenology 1946;56:163-7.
3 Billmire ME, Dyers PA. Serious head injury in infants: accident or abuse. Paediatrics 1985;75:34.

Carty H, Ratcliffe J. The shaken infant syndrome. BMJ 1995;310:344-5.

5 Wilkins B. Head injury - abuse or accident. Arch Dis Child 1997;76:393-7.

6 Hadley MN, Volkes K, Sonnteg H, Rekate HL, Murphy A. The infant surgery 1989·94:536-40.

7 Office for National Statistics. London: HMSO, 1993-5.

8 Department of Health. Confidential enquiry into stillbirths and deaths in infancy (CESDI). Third annual report. London: Department of Health, 1996

9 British Paediatric Surveillance Unit. Sixth annual report. London: British Paediatric Association, 1991.

10 Ludwig S, Barman M. Shaken baby syndrome. A review of 20 cases. Ann Emerg Med 1984;13:104-7.

11 Committee on child abuse and neglect. American Academy of Pediatrics. Shaken infant syndrome: inflicted cerebral trauma. Paediatric 1993;92:872-5

12 Bonnier C, Nassogne M, Evrard P. Outcome and prognosis of whiplash shaken infant syndrome; late consequences after a symptom-free intervals. Dev Med Child Neurol 1995;37:943-56.

13 Caffey J. On the theory and practise of shaking infants. Am J Dis Child 1972;124:161-9.

14 Brown JK, Minns RA. Non-accidental head injury with particular reference to whiplash shaking injury and medico-legal aspects. Dev Med Child Neurol 1993;35:849-69.

15 Showers J. Don't shake the baby: effectiveness of prevention programme Child Abuse Negl 1992;16:11-3.

16 Guthkelch AN. Infantile subdural haematoma and its relationship to whiplash injuries. BMJ 1971;ii:430-1.

17 Alexander R, Crabbe L, Sato Y, Smith W, Bennett T. Serial abuse in children who are shaken. Am J Dis Child 1990;144:58-60.

18 Duhaime AC, Alanio AJ, Lewander WJ, Schut L, Sutton MD, Seidl TS, et al. Head injury in very young children: mechanism, injury types and ophthalmologic findings in 100 hospitalised patients younger than 2 years of age. Paediatrics 1992;20:179-85.

19 Salman M, Crouchman M. What can cause subdural haemorrhage in a term infant? Paediatr Today 1997;5:42-5.

20 Haller JO, Kleinman PK, Merten DF, Cohen HL, Cohen MD, Hayden PW, et al. Diagnostic imaging of child abuse. Pediatrics 1991;87:262-4

21 Alexander RC, Schor DP, Smith WL. Magnetic resonance imaging of intracranial injuries from child abuse. J Paediatr 1986;109:975-9.

22 O'Hare AE, Eden OB. Bleeding disorders and non-accidental injury. Arch Dis Child 1984;59:860-4.

23 Green MA, Lieberman G, Mitroy CM, Parsons MA. Ocular and cerebral trauma in non-accidental injury in infancy: underlying mechanisms and implications for paediatric practice. Br J Ophthalmol 1996;80:282-7.

24 Kaur B, Taylor D. Fundus haemorrhage in infancy. Survey Ophthalmol 1992;37:1-17.

(Accepted 28 July 1998)

\section{Corrections}

Obituary

The wife of Dr Jonathan ("John") James Mercer Kew (26 September, p 890) is called Jocelyn and not Mitch.

Secondary prevention in acute myocardial infarction In this fortnightly review by Rajendra $\mathrm{H}$ Mehta and Kim A Eagle (14 March, pp 838-42), two errors occurred in table 3. Firstly, in the results for the first trial in the "selective" group (Pfeffer et al) the values for relative risk of death should have been 0.19 (0.03 to 0.32$) ; \mathrm{P}=0.019$ [not $0.21(0.05$ to 0.25$)$; $\mathrm{P}=0.014]$. The published values related to the reduction in cardiovascular mortality, not total mortality. Secondly, in the results for the last trial in the selective group (Ambrossioni et al) the values for relative risk of death should have been 0.25 ( 0.11 to $0.60) ; \mathrm{P}=0.19$ [not 0.34 ( 0.08 to 0.54 ); $\mathrm{P}=0.018$ ] The published values related to the combined end point of death or congestive heart failure.

Mammography and the politics of randomised controlled trials

The following information should have been included at the end of this paper by Jane Wells (31 October, pp 1224-9). The author spent six months at the University of Maryland at Baltimore, during which time her salary was paid by the Anglia and Oxford Regional Health Authority. The author thanks Kay Dickersin for advice and help during this stay in Baltimore and for comments on an earlier draft of the paper. 